\section{REVISÃO ABERTA}

\section{O papel da fisioterapia no tratamento da vertigem}

The role of Physical Therapy in vertigo treatment

\section{Marília de Morais Rezende ${ }^{1}$}

1. Fisioterapeuta, Setor de Neuro-Sono da Universidade Federal de São Paulo - Unifesp.

\section{Síntese.}

Trata-se de um estudo retrospectivo, no qual foram colhidos dados de prontuários de 33 pacientes com vertigem em um serviço de fisioterapia a fim de avaliar quais os principais recursos fisioterapêuticos utilizados no tratamento, e seus resultados terapêuticos. Com a avaliação dos dados colhidos o estudo concluiu que as queixas de tontura podem ser tratadas com efetividade utilizando recursos fisioterapêuticos como a terapia manual cervical, reabilitação vestibular, treino de propriocepção e equilíbrio, alongamentos e cuidados posturais ${ }^{1}$.

\section{Resumo.}

No resumo do artigo, o objetivo do trabalho não está bem claro, principalmente quando observada a conclusão.

\section{Introdução.}

$\mathrm{O}$ assunto, vertigem, foi bem abordado na introdução do artigo, porém para melhor compreensão das informações apresentadas poderiam estar expostas seguindo um raciocínio mais didático: o que é vertigem e tontura, a prevalência, classificação de acordo com a topografia da lesão, diagnóstico, tipos de vertigem (VPPB, vertigem cervial), vertigem e a fisioterapia, o objetivo da fisioterapia no tratamento da vertigem, propostas de intervenção fisioterapeutica, cinesioterapia e terapia manual.

No início da introdução foi citada uma informação sobre tontura de origem não vestibular, mas no decorrer do texto não existe mais nenhuma explicação sobre o assunto. Uma explicação bem básica que poderia ser acrescentada e enriqueceria o texto é de que a orientação espacial do corpo resulta de uma integração de estímulos provenientes do sistema vestibular, da visão, e da propriocepção enviada pelo sistema nervoso central. Um comprometimento na integração destes sistemas acarreta em uma disfunção do equilíbrio corporal, que pode ser do tipo tontura ou vertigem ${ }^{2,3}$.

E para finalizar e justificar a finalidade do estudo, poderiam também ser acrescentados resultados de pesquisas que mostram a eficiência da fisioterapia no tratamento da vertigem ${ }^{4}$, incluindo principalmente um estudo que compara pacientes tratados por fisioterapia e tratados com farmacoterapia (tratamento utilizado nos locais onde ainda não se usa fisioterapia), indicando que no caso das vertigens cervicais o tratamento fisioterapêutico é método barato e subutilizado ${ }^{5}$.

\section{Método.}

Na descrição dos procedimentos, no relato sobre o registro nos prontuários, para não parecer que a coleta de dados foi incorreta ou tendenciosa, por não ser exatamente igual em todos os pacientes, poderia ser descrita indicando-se que os testes clínicos convencionais foram relatados apenas em caso de alterações, nos demais casos não foram descritos.
Outra informação que não fica muito clara é de se a avaliação inicial foi refeita, pois é o que subentende-se pelo relato dos procedimentos.

Os dados da Classificação Internacional de Funcionalidade (CIF) poderiam ser acrescentados nos procedimentos, para ficar mais claro, pois foi a forma com que os dados de funcionalidade foram colhidos, e não como foram analisados estatisticamente.

\section{Resultados e Discussâo.}

Os resultados foram muito bem apresentados e as tabelas auxiliam na compreensão, apenas a Tabela 3 apresenta muitos dados que dificultam o entendimento dos números e poderia ser diminuída, deixando-se apenas os dados principais (média, mediana desvio padrão, mínimo e máximo).

$\mathrm{Na}$ discussão, é referido que a presença dos sinais e sintomas predispõe a mudança de hábitos e compromete atividades de trabalho, por isso existem estudos que indicam que a fisioterapia seja direcionada a atividades para compensação central e integração, mas que devem ser incluídas, principalmente no caso da vertigem cervical, ergonomia e fatores psicológicos no tratamento ${ }^{6}$.

A discussão sobre a vertigem cervical pode ser complementada pelas sugestões de alguns autores sobre a vertigem de origem cervical e proprioceptiva e seu tratamento serem motivos de controvérsia, mas as hipóteses que relacionam as tonturas com alterações cervicais baseiam-se no aumento das aferências sensitivas da região cervical, comprometimento do sistema simpático cervical ou ainda na compressão vascular, causadas por processos inflamatórios, traumas, posturas viciosas ou cervico$\operatorname{artroses}^{1,7,8}$.

Também seria interessante acrescentar no capítulo Discussão que, como foi observado nos pacientes desta pesuisa e corroborado com diversos outros estudos, e dependendo da doença, o paciente pode beneficiar-se de manobras de desobstrução e reposicionamento dos cristais, técnicas vestíbulo-oculares, vestíbulo cervicais com estabilização do olhar, exercícios de habituação, adaptação e substituição, ou exercícios físicos destinados a reforçar as aferências proprioceptivas4. Ou ainda, em que alguns casos apenas a terapia manual e cinesioterapia é suficiente para melhora do quadro pela diminuição de tônus da região cervical ou de toda a cadeia muscular posterior.

Os demais temas discutidos como a relação da doença com a diminuição na qualidade de vida, e a uma melhora da independência do paciente e da vida social após o tratamento foram muito bem abordados, e são extremamente importantes para o paciente, muitas vezes mais do que o próprio sintoma em si.

\section{REFERÊNCIAS BIBLIOGRÁFICAS}

1.Teixeira LJ, Prado GF. Impacto da fisioterapia no tratamento da vertigem. Rev Neurocienc 2009;17:112-8.

2.Greters ME, Bittar RSM, Bottino MA, Greters PM. Avaliação do Tratamento Fisioterápico na Vertigem Cervical (Estudo Preliminar). Arq Int Otorrinolaringol 2007;11:406-10.

3.Resende CR, Taguchi CK, Almeida JGd, Fujita RR. Reabilitação vestibular em pacientes idosos portadores de vertigem posicional paroxística benigna. Rev Bras Otorinolaringol 2003;69:348.

4.Boyer FC, Percebois-Macadre L, Regrain E, Leveque M, Taiar $\mathrm{R}$, Seidermann L, et al. Vestibular rehabilitation therapy. Neurophysiol Clin 2008;38:479-87. 
5.Olszewski J, Repetowski M, Kusmierczyk K. Comparative assessment of results in cervical vertigo pharmacotherapy vs physiotherapy treatment. Otolaryngol Pol 2007;61:827-30.

6.Odkvist I, Odkvist LM. Physiotherapy in vertigo. Acta Otolaryngol Suppl 1988;455:74-6.
7.Bracher ES, Almeida CI, Almeida RR, Duprat AC, Bracher CB. A combined approach for the treatment of cervical vertigo. J Manipulative Physiol Ther 2000;23:96-100.

8.Pawlak-Osinska K, Kazmierczak H. Cervical vertigo: etiology, diagnosis and therapy. Pol Merkur Lekarski 2005;19:456-8. 